\title{
Robotic hepatectomy: initial experience of a single institution in Singapore
}

Juinn Huar $\underline{K a m}^{1}$, MBBS, FRCSEd, Brian KP $\underline{G o h}^{1,2}$, MBBS, FRCSEd, Chung-Yip $\underline{C h a n}^{1}$, MMed, FRCSEd, Jen-San Wong ${ }^{1}$, MBBch, FRCSEd, Ser-Yee $\underline{L e e}^{1}$, MBBS, FRCSEd, Peng-Chung $\underline{\text { Cheow }}^{1}$, MBBS, FRCSEd, Alexander YF Chung $^{1}$, MBBS, FRCSEd,

London LPJ Ooi ${ }^{1,2}$, MBBS, FRCSEd

INTRODUCTION In this study, we report our initial experience with robotic hepatectomy.

METHODS Consecutive patients who underwent robotic hepatectomy at Singapore General Hospital, Singapore, from February 2013 to February 2015 were enrolled in this study. The difficulty level of operations was graded using a novel scoring system for laparoscopic hepatectomies.

RESULTS During the two-year period, five consecutive robotic hepatectomies were performed (one left lateral sectionectomy, one non-anatomical segment II/III resection, one anatomical segment $\mathrm{V}$ resection with cholecystectomy, one extended right posterior sectionectomy and one non-anatomical segment V/VI resection). Two hepatectomies were performed for suspected hepatocellular carcinoma, two for solitary liver metastases and one for a large symptomatic haemangioma. The median age of the patients was 53 (range 38-66) years and the median tumour size was 2.5 (range 2.1-7.3) cm. The median total operation time was 340 (range 155-825) minutes and the median volume of blood loss was 300 (range 50-1,200) mL. There were no open conversions and no mortalities or major morbidities (>Clavien-Dindo Grade II). The difficulty level of the operations was graded as low in one case (Score 2), intermediate in three cases (Score 5,6 and 6 ) and high in one case (Score 10). There was one minor morbidity, where the patient experienced Grade A bile leakage, which resolved spontaneously. The median length of postoperative hospital stay was 5 (range 4-7) days. CONCLUSION Our initial experience confirmed the feasibility and safety of robotic hepatectomy.

Keywords: laparoscopic hepatectomy, laparoscopic liver resection, minimally invasive hepatectomy, robotic hepatectomy, robotic liver resection

\section{INTRODUCTION}

Since its introduction in the late eighties, laparoscopic surgery has been increasingly and rapidly adopted in the field of abdominal surgery. Today, in many tertiary centres, laparoscopic surgery is performed on an almost routine basis for abdominal surgical procedures such as appendectomy, ${ }^{(1)}$ cholecystectomy, ${ }^{(2,3)}$ adrenalectomy, ${ }^{(4,5)}$ gastric resection ${ }^{(6)}$ and colectomy. ${ }^{(7)}$ However, the adoption of laparoscopy in hepatectomies has been limited until the last decade, despite the widespread use of laparoscopy in many abdominal procedures; ${ }^{\left({ }^{(8)}\right.}$ this is due to the technical complexity of the procedure, and concerns regarding the adequacy of oncological margins and the risk of bleeding. ${ }^{(9,10)}$

The rapid development of more sophisticated laparoscopic instruments during the past decade has improved the overall safety and reliability of laparoscopic surgery and led to its expansion to more complex operations such as hepatectomies. ${ }^{(11,12)}$ An increasing number of studies have demonstrated that laparoscopic hepatectomy is comparable to conventional open surgery in terms of safety and pathological outcomes, but with the added advantages of laparoscopic surgery. ${ }^{(13-16)}$ However, despite the promising advances in laparoscopic equipment, the inherent limitations of conventional laparoscopy (e.g. restriction in movement and dexterity due to the rigidity of instruments, tremor amplification and lack of depth perception) remain a major hindrance to the adoption and widespread application of laparoscopy in complex abdominal operations. ${ }^{(17)}$ One of the major criticisms of laparoscopic hepatectomy is that it has a relatively long learning curve and limited universal applicability. ${ }^{(18)}$

Robotic surgery was introduced in the 1990s to overcome the limitations of conventional laparoscopic surgery. The robotic platform provides a three-dimensional, high-definition, magnified view of the operative field, as well as improved dexterity and precision (via increased freedom of movement and elimination of tremor). ${ }^{(19,20)}$ However, the superiority of robotic surgery over conventional laparoscopy in performing complex surgical tasks has only been proven in ex vivo models. ${ }^{(19)}$ Presently, the use of robotic technique for hepatectomy remains relatively new and indications for its application remain controversial. ${ }^{(21)}$

In the present study, we report our experience with the first five consecutive robotic hepatectomies in a single institution. We aimed to determine the feasibility and safety of the procedure. To the best of our knowledge, this is the first reported series of robotic hepatectomies in Singapore.

\section{METHODS}

This prospective study was approved by the Review Board at Singapore General Hospital (SGH), Singapore. Five consecutive patients who underwent robotic hepatectomies using the da Vinci ${ }^{\circledR}$

${ }^{1}$ Department of Hepato-pancreato-biliary and Transplantation Surgery, Singapore General Hospital, ${ }^{2}$ Duke-NUS Graduate Medical School, Singapore Correspondence: A/Prof Brian KP Goh, Senior Consultant and Adjunct Associate Professor, Department of Hepato-pancreato-biliary and Transplantation Surgery, Singapore General Hospital, 20 College Road, Academia, Singapore 169856. bsgkp@hotmail.com 
Table I. Summary of demographics and clinical outcomes of the five patients who underwent robotic hepatectomies.

\begin{tabular}{|c|c|c|c|c|c|c|c|c|c|c|c|c|}
\hline Case & $\begin{array}{l}\text { Age (yr), } \\
\text { gender }\end{array}$ & $\begin{array}{l}\text { Preoperative } \\
\text { diagnosis }\end{array}$ & Site & $\begin{array}{l}\text { Size } \\
(\mathrm{cm})\end{array}$ & Final histology & $\begin{array}{c}\text { Closest } \\
\text { margin } \\
(\mathrm{mm})\end{array}$ & $\begin{array}{l}\text { Difficulty } \\
\text { score }^{(23)}\end{array}$ & $\begin{array}{c}\text { Operative } \\
\text { time* } \\
\text { (min) }\end{array}$ & $\begin{array}{l}\text { Docking } \\
\text { time } \\
\text { (min) }\end{array}$ & $\begin{array}{c}\text { PM } \\
\text { time } \\
\text { (min) }\end{array}$ & $\begin{array}{c}\text { Blood } \\
\text { loss } \\
(\mathrm{mL})\end{array}$ & $\begin{array}{c}\text { Hospital } \\
\text { stay } \\
\text { (day) }\end{array}$ \\
\hline 1 & 38 , male & $\begin{array}{l}\text { Symptomatic } \\
\text { haemangioma }\end{array}$ & Segment II/III & 7.3 & $\begin{array}{l}\text { Cavernous } \\
\text { haemangioma }\end{array}$ & 1 & 6 & 305 & 60 & $<30$ & 200 & 5 \\
\hline 2 & 53 , male & $\begin{array}{l}\text { Indeterminate } \\
\text { lesion, possibly } \\
\text { HCC }\end{array}$ & Segment V & 2.1 & $\begin{array}{l}\text { Focal nodular } \\
\text { hyperplasia }\end{array}$ & 2 & 6 & 435 & 30 & 0 & 300 & 4 \\
\hline 3 & 66 , female & $\mathrm{HCC}$ & Segment II/III & 2.6 & $\mathrm{HCC}$ & 20 & 2 & 155 & 10 & 0 & 50 & 4 \\
\hline 4 & 43 , female & $\begin{array}{l}\text { Solitary breast } \\
\text { liver metastasis }\end{array}$ & Segment VII & 2.4 & $\begin{array}{l}\text { Metastatic } \\
\text { adenocarcinoma }\end{array}$ & 1 & 10 & 825 & 40 & 60 & 1,200 & 7 \\
\hline 5 & 62 , male & $\begin{array}{l}\text { Solitary } \\
\text { colorectal liver } \\
\text { metastasis }\end{array}$ & Segment V/VI & 2.5 & $\begin{array}{l}\text { Metastatic } \\
\text { adenocarcinoma }\end{array}$ & 8 & 5 & 340 & 30 & 0 & 800 & 5 \\
\hline
\end{tabular}

*Includes docking time. HCC: hepatocellular carcinoma; PM: Pringle manoeuvre

Si surgical system (Intuitive Surgical Inc, Sunnyvale, CA, USA) from February 2013 to February 2015 at SGH were enrolled in this study. Prior to this study, the surgeons at our institution had the collective experience of more than 2,500 hepatectomies, including over 150 laparoscopic hepatectomies, since the year 2000.

The anatomical location of the lesions and surgical resection were defined according to the Couinaud classification. ${ }^{(22)}$ Liver resections were graded according to the level of difficulty of the laparoscopic resections, based on a novel scoring system proposed by Ban et al, using an index of 1-10: low difficulty 1-3; intermediate difficulty 4-6; and high difficulty $7-10$. $^{(23)}$ In this novel scoring system, the difficulty level of a laparoscopic hepatectomy was scored based on several factors, including the type of resection, location of lesion, size of tumour and proximity of the tumour to major vessels. The choice of surgical approach - laparoscopic, robotic or open - depended on various factors, including the individual surgeon's preference and the patient's choice after thorough discussion of the benefits and limitations of the different approaches. In the present case series, two principal surgeons conducted the five surgeries; Goh BK performed on four cases, while Lee SY performed on one case.

The patients were placed in the reverse Trendelenburg position for surgery. Port placements were similar for all patients, with slight variations made according to the position of the patient's tumour. In general, a 12-mm trocar was inserted in the midline above the umbilicus via the Hassan technique for the robotic camera. Three 8-mm robotic working ports were inserted under laparoscopic guidance at the right upper quadrant, upper midline and left upper quadrant. In the first three cases (Cases 1-3), only two robotic working ports were used and a 12-mm trocar was placed at the right abdomen lateral to the umbilicus for the bedside assistant. In selected cases, an additional 5-mm assistant port and/or a 5-mm epigastric port was inserted for the Pringle manoeuvre, if deemed necessary. The robotic system was brought into position over the patient's left or right shoulder, depending on the tumour location, and docked after placement of the ports. The assistant surgeon was positioned between the patient's legs.
Laparoscopic intraoperative ultrasonography was routinely performed and liver parenchymal transection was performed using robotic harmonic scalpel, monopolar cautery hook/ scissors and fenestrated bipolar diathermy forceps. Liver parenchymal transection was performed with the harmonic scalpel using a combination of clamp-crushing or direct sealing/cutting techniques. Conventional laparoscopic instruments were used by the assistant for retraction, suction or application of clips. In the remaining two cases (Cases 4 and 5), a laparoscopic cavitron ultrasonic surgical aspirator (CUSA; Valleylab, Boulder, CO, USA) was used to assist in parenchymal transection. After the resection was completed, the specimen was extracted through an extension of the supraumbilical or assistant port site using the Endobag ${ }^{\mathrm{TM}}$. Operative (including docking) time, total volume of operative blood loss and length of postoperative hospital stay after surgery were recorded. Any postoperative complications encountered up to six months after the surgery were recorded using the Clavien-Dindo classification. ${ }^{(24)}$

\section{RESULTS}

During the study period, five consecutive patients underwent robotic hepatectomy. The type of hepatectomy performed and the indications for hepatectomy are as follows: anatomical left lateral sectionectomy for a haemangioma $(n=1)$; nonanatomical segment II/III resection for a hepatocellular carcinoma $(\mathrm{n}=1)$; anatomical segment $\mathrm{V}$ resection with cholecystectomy for a focal nodular hyperplasia $(n=1)$; extended right posterior sectionectomy for breast liver metastasis $(n=1)$; and resection of segments V/VI for colorectal liver metastasis $(n=1)$.

The characteristics of the five patients are summarised in Table I. The median age was 53 (range 38-66) years and the median tumour size was 2.5 (range $2.1-7.3$ ) $\mathrm{cm}$. The median total operation time (including docking time) was 340 (range 155-825) minutes, while the median volume of blood loss was 300 (range $50-1,200) \mathrm{mL}$. The difficulty level of one of the operations was graded as low (i.e. Score 2), while three operations were graded as intermediate (i.e. Scores 5, 6 and 6) and one was graded as high (i.e. Score 10). None of the patients required open conversion, 
and none had mortalities or major morbidities (i.e. greater than Clavien-Dindo Grade II) up to three months after the surgery. There was a minor morbidity in one case; the patient experienced Grade A bile leakage, which resolved spontaneously. All final resection margins were clear $(\geq 1 \mathrm{~mm})$, and the median length of hospital stay was 5 (range 4-7) days. The following are brief descriptions of the five cases.

\section{Case 1}

The first case, performed in February 2013, involved a 38-yearold man who presented with abdominal discomfort. He had no significant past medical history. Computed tomography of the abdomen revealed a large segment II/III haemangioma (measuring $7.3 \mathrm{~cm}$ at its largest diameter) abutting the left hepatic and portal veins (Fig. 1). Robotic anatomical left lateral sectionectomy was performed and the Pringle manoeuvre was applied for less than 30 minutes. Estimated volume of blood loss was $200 \mathrm{~mL}$. The patient was discharged from the hospital after five days, and remained well and symptom-free one year after the surgery. Final histology confirmed a cavernous haemangioma.

\section{Case 2}

A 53-year-old man with chronic hepatitis B was detected to have a segment $\mathrm{V}$ tumour on surveillance ultrasonography. Magnetic resonance $(M R)$ imaging revealed an indeterminate arterial enhancing lesion (measuring $2.1 \mathrm{~cm}$ ) with atypical washout pattern in the portal venous phase (Fig. 2). The patient underwent robotic laparoscopic cholecystectomy and resection of segment V. Bile-stained fluid was noted in the drain postoperatively. The patient was discharged on postoperative Day 4 and the drain was removed in the outpatient clinic three days after discharge. Final histology of the tumour demonstrated a focal nodule hyperplasia with clear margins.

\section{Case 3}

A 66-year-old woman with chronic hepatitis B was found to have a 2.6-cm segment II/III tumour, which was characterised as a hepatocellular carcinoma on MR imaging. She underwent nonanatomical resection of segment II/III. The tumour was confirmed on final histology to be a hepatocellular carcinoma with clear resection margins. The patient recovered well and was discharged on postoperative Day 4.

\section{Case 4}

A 43-year-old woman was detected with solitary metachronous liver metastasis after previous mastectomy and adjuvant chemotherapy for breast cancer. MR imaging demonstrated a 2.4-cm segment VII lesion involving the right hepatic vein. The lesion was located close to the junction of the right hepatic vein and inferior vena cava (Fig. 3). Due to the patient's long disease-free interval (> 24 months), she was offered the option of surgical resection. She underwent anatomical extended right posterior sectionectomy (including the right hepatic vein) and cholecystectomy. The patient's postoperative recovery was uncomplicated and she was discharged on postoperative Day 7.

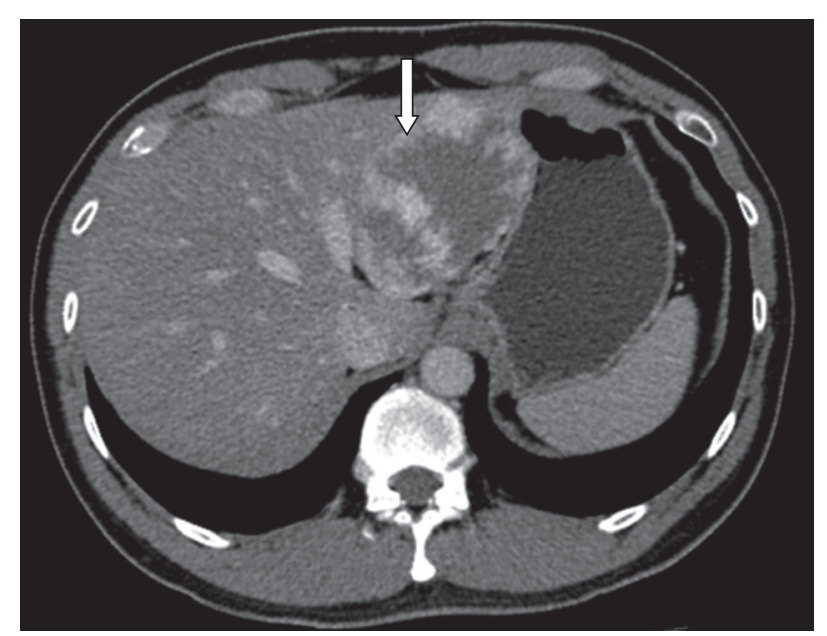

Fig. 1 Case 1: CT image of the abdomen shows a large symptomatic segment II/III haemangioma (arrow) abutting the left hepatic vein and portal vein.

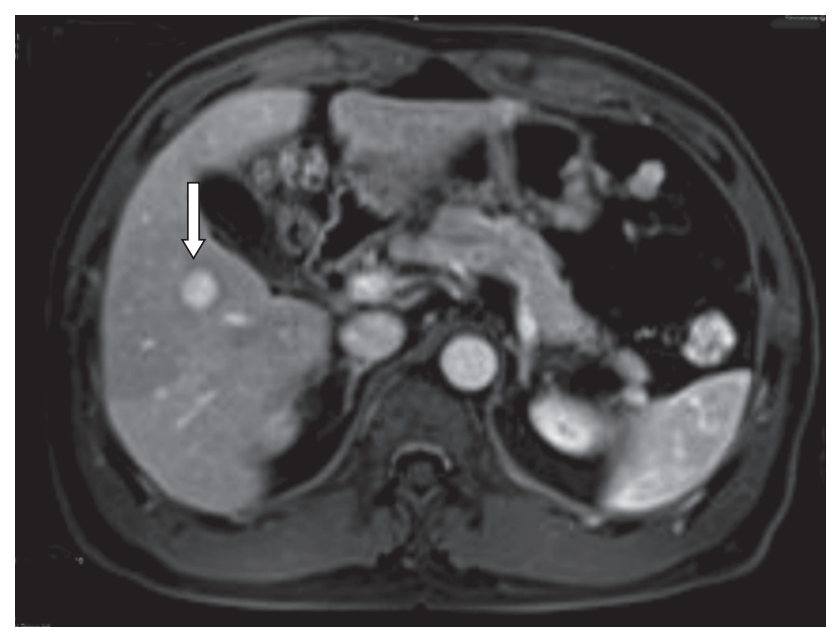

Fig. 2 Case 2: MR image of the liver of the patient (who has chronic hepatitis B) shows an indeterminate segment $\mathrm{V}$ lesion (arrow).

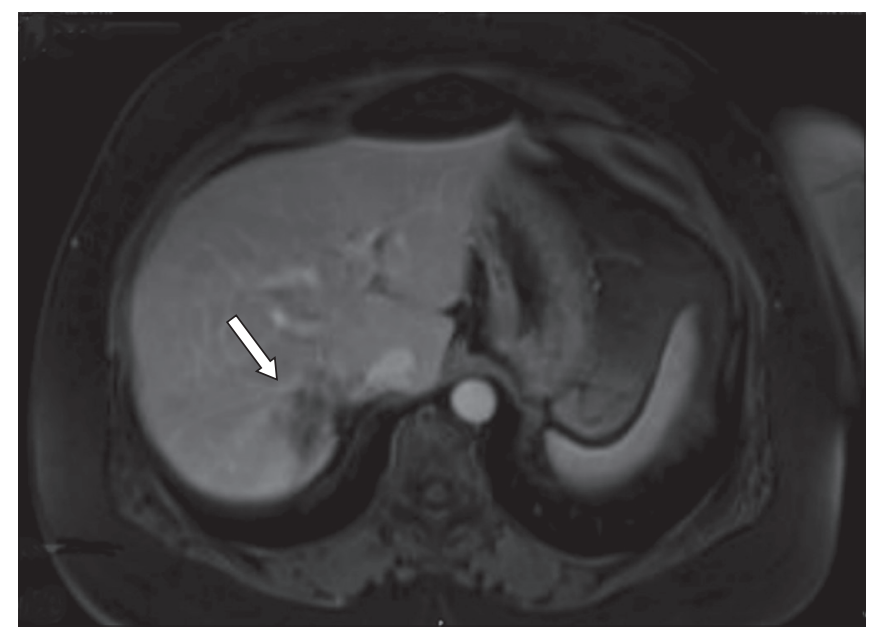

Fig. 3 Case 4: MR image of the liver shows a solitary liver metastasis (arrow) at segment VII, close to the root of the right hepatic vein and inferior vena cava.

\section{Case 5}

A 62-year-old man presented with synchronous liver metastasis from an obstructing distal colonic adenocarcinoma with gallbladder stone. The patient underwent colonic stenting 


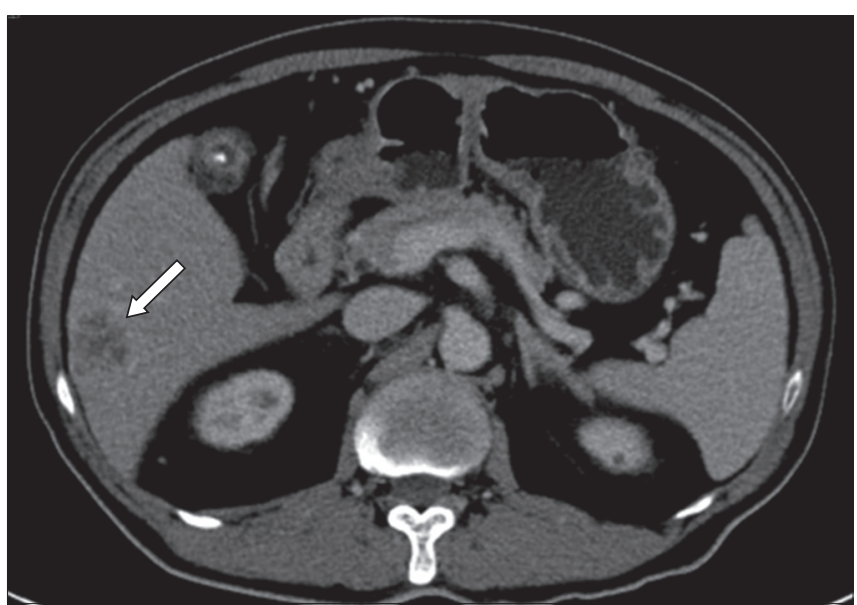

Fig. 4 Case 5: MR image of the liver shows a solitary liver metastasis (arrow) at segment $\mathrm{V} / \mathrm{VI}$, with gallbladder stone.

followed by laparoscopic anterior resection. Despite adjuvant chemotherapy, solitary segment V/VI liver metastasis was noted to have increased in size, from $1.7 \mathrm{~cm}$ to $2.5 \mathrm{~cm}$ (Fig. 4). The patient subsequently underwent robotic resection of segment $\mathrm{V} /$ $\mathrm{VI}$ and cholecystectomy. He recovered well and was discharged on postoperative Day 5.

\section{DISCUSSION}

To date, hepatectomy remains one of the most technically challenging abdominal operations to perform, as the liver is a highly vascularised organ with a unique and complex vasculature and biliary drainage system. Although the mortality rate after liver resections has decreased significantly with improved surgical techniques and perioperative care, morbidity rates remain high. ${ }^{(25}$ Perioperative haemorrhage and bile leakage are the most common complications after hepatectomy. ${ }^{(26)}$ Due to its technical complexity, it is not surprising that the surgical community has been comparatively slow to adopt the laparoscopic approach for hepatectomies compared to other types of abdominal operations.

In the last decade, the adoption of laparoscopic hepatectomy has increased exponentially worldwide as a result of advancements in surgical technique and laparoscopic equipment. ${ }^{(11,27)}$ Today, its adoption is hindered mainly by the reportedly steep learning curve, especially for major hepatectomies; it is also doubtful whether the promising results reported by expert, high-volume centres are applicable to lower-volume centres. In an early study conducted by pioneering surgeons, it was reported that about 60 cases may be required for a surgeon to achieve competency in laparoscopic hepatectomy. ${ }^{(18)}$ However, more recent studies have reported that the learning curve may be shortened to about 20 cases, especially for minor laparoscopic hepatectomies. ${ }^{(9,28)}$

Robotic surgery was introduced to overcome the limitations of conventional laparoscopic surgery. ${ }^{(29,30)}$ It has been hypothesised that for experienced surgeons who are only familiar with the open approach, the learning curve for robotic surgery may be less steep than that for conventional laparoscopy. ${ }^{(29-31)}$ This is due to the fact that the robot is built to mimic a surgeon's hands; in other words, open surgical techniques are more readily translated to robotic surgery than laparoscopic surgery. ${ }^{(30)}$
Despite its many theoretical advantages, robotic surgery is associated with several limitations. Currently, its main limitation is cost, which has been reported to be several times higher than that of conventional laparoscopic surgery. ${ }^{(32)}$ Its high cost has resulted in many surgeons having no or limited access to the technology. In addition, the size and bulkiness of the current robotic platform could result in arm collision during manipulation, limiting the robot's movement. There is also the absence of tactile feedback from the robotic arms, forcing surgeons to rely on experience and imagination during organ retraction and suturing. ${ }^{(33)}$ Furthermore, any change in the position of the patient would require the robot to be re-docked. The surgical and operating room teams need to undergo specialised training in order to dock the robot and exchange the surgical instruments on the robotic arms. Some authors have attributed the time spent docking and changing instruments to be one of the main reasons robotic surgery generally takes longer than conventional laparoscopic surgery, especially during the learning phase. ${ }^{(34)}$ It has been suggested that experience with at least ten robotic procedures is required to master robot-assisted laparoscopic surgery, and that a skilled assistant is needed to handle suction and stapling devices, especially for complex operations. ${ }^{(33)}$

Presently, robotic hepatectomy is a relatively new procedure with limited studies published worldwide. ${ }^{(33,34)}$ Most of the published studies involved a small retrospective series of patients, and demonstrated that robotic hepatectomy is safe and feasible when performed by experienced surgeons. ${ }^{(31,34,35)}$ Nonetheless, there is evidence to suggest that robotic hepatectomy may be superior to conventional laparoscopy. For instance, a study by Tsung et al demonstrated that patients who underwent robotic hepatectomy were less likely to require conversion to hand-assisted surgery as compared to those who underwent laparoscopic hepatectomy. ${ }^{(34)}$ Another study reported that robot-assisted surgery may be more advantageous than conventional laparoscopic surgery when dealing with intraoperative complications (e.g. major vascular injury) during hepatectomies. ${ }^{(36)}$ Pelletier et al reported in their systematic review that robotic hepatectomy enabled intracorporeal suturing and tying in difficult locations, as well as efficient control and management of bleeding, such that the need for conversion to open surgery was reduced. ${ }^{(35)}$ As with laparoscopic hepatectomy, most reported cases of robotic hepatectomy were performed in highly specialised tertiary referral centres. While most of the aforementioned studies reported promising short-term outcomes, the long-term oncological outcomes and cost-effectiveness of the procedure remain unanswered. Pelletier et al reported that robotic hepatectomy was associated with increased cost and longer operating time as compared to conventional laparoscopic surgery, ${ }^{(35)}$ while a more recent systematic review reported that not only was laparoscopic hepatectomy associated with shorter operating time, but it also decreased the volume of blood loss as compared to robotic hepatectomy. ${ }^{(37)}$ In other words, based on the current literature, there is limited evidence to support the superiority of robotic hepatectomy over conventional laparoscopic hepatectomy. 
The results of our initial experience with robotic hepatectomy were consistent with the findings in the literature. In all five cases, robotic hepatectomy was successfully completed without the need for conversion to open or hand-assisted surgery. This was despite the fact that three of the five cases were graded to be of intermediate difficulty and one was graded to be of high difficulty. It is vital to highlight that an important confounding factor in the present study was that our team of surgeons had considerable experience with laparoscopic hepatectomy prior to embarking on robotic hepatectomy. The operating times for the five cases were relatively long; this could be due in part to the initial learning curve and the difficulty level of the cases. Nonetheless, it is important to emphasise that despite the long surgical times, none of the five patients experienced any major complications. We found that the superiority of the robot in performing fine suturing in tight spaces allowed for better control and haemostasis of bleeding vessels. We experienced this advantage in Case 2 (bile leakage from the segment $\mathrm{V}$ pedicle was oversewn) and Case 4 (bleeding from torn tributaries of the right hepatic vein was sutured). Other advantages of using the robot include the highdefinition, three-dimensional visualisation, and the increased stability and dexterity of the robotic arms (which allowed for more precise dissection and transection of the liver, especially during transaction of the superior aspects of parenchymal transection). We were not able to assess the other reported benefits of robotic hepatectomy, such as the robot's performance in biliary-enteric anastomosis and porta hilar dissection, as these procedures were not performed in the present study.

Some of the technical limitations that we encountered with the robot were the lack of tactile feedback and the limited number of robotic instruments available for hepatectomy (as compared to conventional laparoscopy). The former can be partly overcome by improved three-dimensional visualisation and the presence of an expert surgeon at the bedside for surgical assistance, especially for suctioning. An example of the latter limitation is the lack of a laparoscopic CUSA for the robot. The laparoscopic CUSA is an instrument that we preferentially use for complex resections that require careful dissection around major vascular pedicles. As this instrument was not available with the robotic system, we had to rely on the assistant surgeon to drive this instrument in a robotic-laparoscopic hybrid technique for Cases 4 and 5.

In our opinion, robotic surgery is currently not in competition with, but rather, complementary to conventional laparoscopic hepatectomy. The application of robotic assistance in laparoscopic hepatectomy may be useful in expanding the indications for laparoscopic hepatectomy to more technically challenging procedures, and this would allow more patients to enjoy the benefits of minimally invasive surgery. Our initial experience with robotic hepatectomy demonstrated that the procedure is feasible and safe, even for hepatectomies that were graded to be of intermediate or high difficulty. Further studies involving larger patient cohorts are needed to determine whether robotic hepatectomy is superior and more cost-effective than conventional laparoscopic hepatectomy.

\section{DISCLOSURE}

Goh BK, Chan CY, Lee SY and Wong JS received travel support from Transmedic Pte Ltd, the local distributor of the da Vinci robotic system in Singapore.

\section{REFERENCES}

1. Goh BK, Chui CH, Yap TL, et al. Is early laparoscopic appendectomy feasible in children with acute appendicitis presenting with an appendiceal mass? A prospective study. J Pediatric Surg 2005; 40:1134-7.

2. Purkayastha S, Tilney HS, Georgiou P, et al. Laparoscopic cholecystectomy versus mini-laparotomy cholecystectomy: a meta-analysis of randomised control trials. Surg Endosc 2007; 21:1294-300.

3. Polychronidis A, Laftsidis P, Bounovas A, Simopoulos C. Twenty years of laparoscopic cholecystectomy: Philippe Mouret--March 17, 1987. JSLS 2008; 12:109-11.

4. Goh BK, Tan YH, Yip SK, Eng PH, Cheng CW. Outcome of patients undergoing laparoscopic adrenalectomy for primary hyperaldosteronism. JSLS 2004; 8:320-5.

5. Morino M, Benincà G, Giraudo G, et al. Robot-assisted vs laparoscopic adrenalectomy: a prospective randomized controlled trial. Surg Endosc 2004; 18:1742-6.

6. Koh YX, Chok AY, Zheng HL, et al. A systematic review and meta-analysis comparing laparoscopic versus open gastric resection for gastrointestinal stromal tumors of the stomach. Ann Surg Oncol 2013; 20:3549-60.

7. Law WL, Lee YM, Choi HK, Seto CL, Ho JW. Impact of laparoscopic resection for colorectal cancer on operative outcomes and survival. Ann Surg 2007; 245:1-7.

8. Cherqui D, Husson E, Hammoud R, et al. Laparoscopic liver resections: a feasibility study in 30 patients. Ann Surg 2000; 232:753-62.

9. Goh BK, Chan CY, Wong JS, et al. Factors associated with and outcomes of open conversion after laparoscopic minor hepatectomy: initial experience at a single institution. Surg Endosc 2015; 29:2636-42.

10. Reddy SK, Tsung A, Geller DA. Laparoscopic liver resection. World J Surg 2011; 35:1478-86.

11. Nguyen KT, Gamblin TC, Gellar DA. World review of laparoscopic liver resection-2,804 patients. Ann Surg 2009; 250:831-41.

12. Koffron A, Geller D, Gamblin TC, Abecassis M. Laparoscopic liver surgery: Shifting the management of liver tumors. Hepatology 2006; 44:1694-700.

13. Cho JY, Han HS, Yoon YS, Shin SH. Outcomes of laparoscopic liver resection for lesions located in the right side of the liver. Arch Surg 2009; 144:25-9.

14. Abu Hilal M, Di Fabio F, Abu Salameh M, Pearce NW. Oncological efficiency analysis of laparoscopic liver resection for primary and metastatic cancer: a single-center UK experience. Arch Surg 2012; 147:42-8.

15. Buell JF, Cherqui D, Geller DA, et al; World Consensus Conference on Laparoscopic Surgery. The international position on laparoscopic liver surgery: The Louisville Statement, 2008. Ann Surg 2009; 250:825-30.

16. Wakabayashi G, Cherqui D, Geller DA, et al. Recommendations for laparoscopic liver resection: a report from the second international consensus conference held in Morioka. Ann Surg 2015; 261:619-29.

17. Kitisin K, Packiam V, Bartlett DL, Tsung A. A current update on the evolution of robotic liver surgery. Minerva Chir 2011; 66:281-93.

18. Vigano L, Laurent A, Tayar C, et al. The learning curve in laparoscopic liver resection: improved feasibility and reproducibility. Ann Surg 2009; 250:772-82.

19. Wilson EB. The evolution of robotic general surgery. Scand J Surg 2009; 98:125-9.

20. Strijker M, van Santvoort HC, Besselink MG, et al. Robot-assisted pancreatic surgery: a systematic review of the literature. HPB (Oxford) 2013; 15:1-10.

21. Leung U, Fong Y. Robotic liver surgery. Hepatobiliary Surg Nutr 2014; 3:288-94.

22. Strasberg SM. Nomenclature of hepatic anatomy and resection: a review of Brisbane 2000 system. J Hepatobiliary Pancreat Surg 2005; 12:351-5.

23. Ban D, Tanabe $M$, Ito $H$, et al. A novel difficulty scoring system for laparoscopic liver resection. J Hepatobiliary Pancreat Sci 2014; 21:745-53.

24. Dindo D, Demartines N, Clavien PA. Classification of surgical complications: a new proposal with evaluation in a cohort of 6336 patients and results of a survey. Ann Surg 2004; 240:205-13.

25. Fan ST, Lo CM, Liu CL, et al. Hepatectomy for hepatocellular carcinoma: toward zero hospital deaths. Ann Surg 1999; 229:322-30.

26. Fan ST, Mau Lo C, Poon RT, et al. Continuous improvement of survival outcomes of resection of hepatocellular carcinoma: a 20-year experience. Ann Surg 2011; 253:745-58. 
27. Buell JF, Thomas MT, Rudich S, et al. Experience with more than 500 minimally invasive hepatic procedures. Ann Surg 2008; 248:475-86.

28. Cai X, Li Z, Zhang Y, et al. Laparoscopic liver resection and the learning curve: a 14-year, single-center experience. Surg Endosc 2014; 28:1334-41.

29. Lanfranco AR, Castellanos AE, Desai JP, Meyers WC. Robotic surgery: a current perspective. Ann Surg 2004; 239:14-21.

30. Daouadi M, Zureikat AH, Zenati MS, et al. Robot-assisted minimally invasive distal pancreatectomy is superior to the laparoscopic technique. Ann Surg 2013; 257:128-32.

31. Lai EC, Tang CN, Yang GP, Li MK. Multimodality laparoscopic liver resection for hepatic malignancy--from conventional total laparoscopic approach to robotic-assisted laparoscopic approach. Int J Surg 2011; 9:324-8.

32. Turchetti G, Palla I, Pierotti F, Cuschieri A. Economic evaluation of da Vinci-assisted robotic surgery: a systematic review. Surg Endosc 2012; 26:598-606.
33. Giulianotti PC, Coratti A, Angelini M, et al. Robotics in general surgery: personal experience in a large community hospital. Arch Surg 2003; 138:777-84.

34. Tsung A, Geller DA, Sukato DC, et al. Robotic versus laparoscopic hepatectomy: a matched comparison. Ann Surg 2014; 259:549-55.

35. Pelletier JS, Gill RS, Shi X, Birch DW, Karmali S. Robotic-assisted hepatic resection: a systematic review. Int J Med Robot 2013; 9:262-7.

36. Boggi U, Moretto C, Vistoli F, D'Imporzano S, Mosca F. Robotic suture of a large caval injury caused by endo-GIA stapler malfunction during laparoscopic wedge resection of liver segments VII and VIII en-bloc with right hepatic vein. Minim Invasive Ther Allied Technol 2009; 18:306-10.

37. Montalti R, Berardi G, Patriti A, Vivarelli M, Troisi RI. Outcomes of robotic vs laparoscopic hepatectomy: A systematic review and meta-analysis. World J Gastroenterol 2015; 21:8441-51. 